\title{
Epidemiology of senile prostatic enlargement among elderly men in Arar, Kingdom of Saudi Arabia
}

Abdullah Barghash Alanazi ${ }^{1}$, Anfal Muaddi Alshalan ${ }^{2}$, Omar Ayed Alanazi ${ }^{1}$, Munif Salah Alanazi ${ }^{1}$, Abdulaziz Inad Alanazi ${ }^{1}$, Abdullah Hussain Alanazi ${ }^{2}$, Anwar Mohammed Alhadhari ${ }^{2}$, Ahmed Saad Alanazi ${ }^{2}$, Rahmah Abdulhadi Alanazi ${ }^{2}$, Ibtisam Matan Alanazi ${ }^{1}$, Mohammed Abdullah Alanazi ${ }^{2}$, Mohammed Abdullah Alkhidhr ${ }^{2}$, Hassan Ali Aldehneen ${ }^{3}$, Raed Khalid Alanazi ${ }^{1}$

\footnotetext{
${ }^{1}$ Intern, Northern Border University, Arar, Saudi Arabia

${ }^{2}$ Medical Student, Northern Border University, Arar, Saudi Arabia

${ }^{3}$ Intern, Imam Abdulrahman Bin Faisal University, Dammam, Saudi Arabia
}

\section{Type of article: Original}

\begin{abstract}
Background and aim: Senile prostatic enlargement due to benign prostatic hyperplasia (BPH) is a common problem among older men, and is responsible for considerable disability. This study was conducted to determine the prevalence and determinants of the clinically diagnosed prostatic enlargement among elderly men in Arar, Northern Saudi Arabia.

Methods: This cross-sectional study was carried out on all consented elderly males attending the outpatient clinic of the urology department of Arar Central Hospital from February 2017 to July 30, 2017. Each participant underwent a general examination and digital per rectal to detect general chronic diseases, obesity and prostatic enlargement. Data were analyzed by SPSS version 16, using descriptive statistics and Chi-squared test.

Results: Among 81 elderly male participants in the study, 19.8\% had clinically diagnosed senile prostatic enlargement (SPE) and 3.7\% had prostatic tumors. There was significant relation between SPE and age as $6.2 \%$ of cases were $60-69$ years, $43.8 \%$ were $70-79$ years and $44.0 \%$ were 80 years or more $(\mathrm{p}<0.05)$. There was also significant relation between SPE and obesity as $62.5 \%$ of cases were obese and $37.5 \%$ were non obese $(p<0.05)$. There was no significant relation with marital status, smoking or diabetes mellitus $(\mathrm{p}<0.05)$.

Conclusion: Senile prostatic enlargement is one of the significant important issues in public health in Arar city, Northern Saudi Arabia. The prevalence of this condition reaches 19.3\%, thereby placing even greater burden on the quality of life of the elderly and on the health system in the region.

Keywords: Senile prostatic enlargement; Benign prostatic hyperplasia; Prevalence; Arar; Saudi Arabia
\end{abstract}

\section{Introduction}

Benign prostatic hyperplasia (BPH) relates to the nonmalignant growth of the prostate, commonly seen in the elderly male population. The many definitional complications related to $\mathrm{BPH}$ lead to further problems with calculations, source of incidence and prevalence rates. Despite many previous researches, the etiology of BPH is still not clearly understood (1). BPH is also a potential cause for physical compression of the urethra that results in anatomic bladder outlet obstruction (2). The symptoms of benign prostatic hyperplasia are generally referred to as "lower urinary tract symptoms" or LUTS (3), and are classified as storage, voiding, and symptoms occurring after urination (4). Voiding symptoms are comprised of intermittency, dribbling, straining, hesitancy, and a decrease in caliber of urine stream (5). Storage symptoms are comprised of the urge to urinate frequently, waking up to urinate throughout the night, feeling of urgency, involuntary urination which includes involuntary urination during sleep, or urge incontinence (6). Analytical epidemiological research has been carried out in order to evaluate risk factors involving the development of benign prostatic hyperplasia. The risk factors associated with BPH are put into two general categories: modifiable (diet, obesity, sex steroid hormones, the metabolic syndrome, diabetes, inflammation, and physical activity) and non-modifiable (age, genetics and geography) (7). Diagnosis of benign prostatic hyperplasia is

\section{Corresponding author:}

Abdullah Barghash Alanazi, Northern Border University.

Tel: 0545674144, Email: Mbbs.abdullah1229@gmail.com

Received: July 14, 2017, Accepted: August 21, 2017, Published: September 2017

iThenticate screening: August 21, 2017, English editing: September 14, 2017, Quality control: September 16, 2017

(C) 2017 The Authors. This is an open access article under the terms of the Creative Commons Attribution-NonCommercialNoDerivs License, which permits use and distribution in any medium, provided the original work is properly cited, the use is non-commercial and no modifications or adaptations are made. 
attained from patients' medical history and a digital per rectal examination (8). Incidence of benign prostatic hyperplasia is relatively common in men and onset of symptoms can be as early as age thirty. By age fifty, up to $50 \%$ of men show histologic evidence of BPH symptoms which usually increases with age (1). Prevalence of histologically diagnosed prostatic hyperplasia increases from $8 \%$ in 31 to 40 -year-old men, to 40 - $50 \%$ in 51 to 60 year-old men, and to over $80 \%$ in men older than 80 years (9). Observational studies from the US, Europe and Asia have established that older age is a risk factor for BPH onset and clinical progression by a number of different metrics (10-16). This study was conducted to show the prevalence and determinants of clinically diagnosed prostatic enlargement among elderly men in Arar, Northern Saudi Arabia.

\section{Material and Methods}

A cross-sectional study was carried out in Arar city, Northern Saudi Arabia, KSA. This study was conducted during the period from February 2017 to July 30, 2017, on all consented elderly males (more than 60 years old) attending the outpatient clinic of the urology department of Arar Central Hospital. Each participant underwent a general examination and digital per rectal to detect general chronic diseases, obesity and prostatic enlargement. A predesigned questionnaire was used for data collection. Data was collected from 81 elderly males aged from 60 to +90 years old. The pre designed questionnaire included questions designed to fulfill the study objectives. The questionnaire consisted of questions and checklists about socio-demographic characteristics (age, educational level, marital status and occupational status), and questions about chronic diseases, body mass index (BMI) and smoking status, and presence of senile enlarged prostate (SEP) and prostatic tumors. All the data were analyzed by SPSS version 16 (SPSS Inc., Chicago, Illinois, USA) through descriptive statistics and Chi-squared test. P-value of less than 0.05 was considered statistically significant. Permission to conduct the study was obtained from the Research and Ethics Committee at the College of Medicine, Northern Border University, Arar, Saudi Arabia. The questionnaire had a brief introduction explaining the aims and significance of the study.

\section{Results}

Table 1 illustrates socio-demographic characteristics of the cases, chronic diseases and BMI status of the studied elderly population. In total, $29.6 \%$ of the studied cases were aged less than $60,35.8 \%$ between $(60-70), 27.2 \%$ between (70-80) and only 7.4\% more than 90 years old (mean age was $70 \pm 9.25$ ). Of these, 90.1\% were married, $28.4 \%$ were highly educated, and $56.8 \%$ of them were retired.

Table 1. Socio-demographic characteristics, chronic diseases and BMI status of the studied elderly population, Arar, 2016

\begin{tabular}{|c|c|c|c|}
\hline \multicolumn{2}{|l|}{ Variables } & $\mathrm{n}$ & $\%$ \\
\hline \multirow[t]{3}{*}{ Age (years); $70 \pm 9.25$} & $<60$ & 24 & 29.6 \\
\hline & $60-70$ & 29 & 35.8 \\
\hline & $>70$ & 28 & 34.6 \\
\hline \multirow[t]{4}{*}{ Marital status } & Widow & 3 & 3.7 \\
\hline & Single & 3 & 3.7 \\
\hline & Married & 73 & 90.1 \\
\hline & Divorced & 2 & 2.5 \\
\hline \multirow[t]{5}{*}{ Educational level } & Illiterate & 22 & 27.2 \\
\hline & Primary & 17 & 21.0 \\
\hline & Preparatory & 9 & 11.1 \\
\hline & Secondary & 10 & 12.3 \\
\hline & University or more & 23 & 28.4 \\
\hline \multirow[t]{3}{*}{ Working status } & Shepherd & 15 & 18.5 \\
\hline & No work & 20 & 24.7 \\
\hline & Retired & 46 & 56.8 \\
\hline \multirow[t]{3}{*}{ Chronic diseases } & $\mathrm{DM}$ & 24 & 29.6 \\
\hline & Hypertension & 30 & 37.0 \\
\hline & IHD & 11 & 13.6 \\
\hline \multirow[t]{3}{*}{ Smoking } & Non- smoker & 44 & 54.3 \\
\hline & Smokers & 15 & 18.5 \\
\hline & Ex-smokers & 22 & 27.2 \\
\hline
\end{tabular}


Regarding chronic diseases and BMI status; $37 \%$ of the cases had hypertension, $29.6 \%$ had DM and $13.6 \%$ had IHD. Mean BMI $( \pm$ SD) was $29.99 \pm 9.73$. Only $18.5 \%$ of the cases were smokers. Our findings showed that 16 participants $(19.8 \%)$ had senile prostatic enlargement and three participants $(3.7 \%)$ had prostatic tumors; while 62 participants (76.5\%) had normal prostate. Table 2 illustrates the relationship between sociodemographic characteristics, smoking history, presence of DM and obesity and presence of SPE among the studied elderly population. There was significant relation between SPE and age as $6.2 \%$ of cases were $60-69$ years, $43.8 \%$ were 70 79 years and $44.0 \%$ were 80 years or more $(\mathrm{p}<0.05)$. There was also significant relation between SPE and obesity as $10(62.5 \%)$ of the cases were obese and $6(37.5 \%)$ were non-obese $(\mathrm{p}<0.05)$. There was no significant relation with marital status, smoking or diabetes $(\mathrm{p}<0.05)$.

Table 2. Relationship between sociodemographic characteristics, smoking history, presence of DM and prostate gland status among the studied elderly population, Arar, 2017

\begin{tabular}{|c|c|c|c|c|c|}
\hline \multirow{2}{*}{\multicolumn{2}{|c|}{ Variable }} & \multicolumn{2}{|c|}{ Senile Prostatic enlargement; $\mathrm{n}(\%)$} & \multirow[t]{2}{*}{ Total $(n=81) ; n(\%)$} & \multirow[t]{2}{*}{$\mathrm{p}$-value } \\
\hline & & SPE $(n=16)$ & $\mathrm{n}(\mathrm{n}=65)$ & & \\
\hline \multirow[t]{3}{*}{ Age group (years) } & $<60$ & $1(6.2)$ & $23(35.4)$ & $24(29.6)$ & \multirow[t]{3}{*}{0.016} \\
\hline & $60-70$ & $7(43.8)$ & $22(33.8)$ & $29(35.8)$ & \\
\hline & $>70$ & $8(44.0)$ & $20(30.8)$ & $28(34.6)$ & \\
\hline \multirow[t]{4}{*}{ Marital status } & Widow & $1(6.2)$ & $2(3.1)$ & $3(3.7)$ & \multirow[t]{4}{*}{0.170} \\
\hline & Single & $0(0.0)$ & $3(4.6)$ & $3(3.7)$ & \\
\hline & Married & $14(87.5)$ & $59(90.8)$ & $73(90.1)$ & \\
\hline & Divorced & $1(6.2)$ & $1(1.5)$ & $2(2.5)$ & \\
\hline \multirow[t]{3}{*}{ Smoking history } & Non- smoker & $8(50.0)$ & $36(55.4)$ & $44(54.3)$ & \multirow[t]{3}{*}{0.204} \\
\hline & Smokers & $3(18.8)$ & $12(18.4)$ & $15(18.5)$ & \\
\hline & Ex-smoker & $5(31.2)$ & $17(26.1)$ & $22(27.2)$ & \\
\hline \multirow[t]{2}{*}{ Diabetes mellitus } & Yes & $7(43.8)$ & $17(26.1)$ & $24(29.6)$ & \multirow[t]{2}{*}{0.316} \\
\hline & No & $9(56.2)$ & $48(73.8)$ & $57(70.4)$ & \\
\hline \multirow[t]{2}{*}{ Obesity } & Yes & $10(62.5)$ & $11(16.9)$ & $21(25.9)$ & \multirow[t]{2}{*}{0.041} \\
\hline & No & $6(37.5)$ & $54(83.1)$ & $60(74.1)$ & \\
\hline
\end{tabular}

\section{Discussion and conclusions}

Senile prostatic enlargement is one of the most common diseases among the elderly. It is a common problem that affects the quality of life in approximately one third of men older than 50 years (17). Our study was conducted to estimate the prevalence and determinants of the clinically diagnosed senile prostatic enlargement in Arar, Northern Saudi Arabia. In the current study, there was significant relation between SPE and age $(p<0.05)$. A recent study by Alghamidi et al. in 2013 (18) showed that the incidence is higher than expected, with an age-standardized incidence rate of up to 10.1 in the eastern region. One further study by Al-Abdin et al. (19) investigated the detection rate of prostate cancer in a cohort of Saudi men compared to their Canadian counterparts; it was evident from their report that there was a significantly low detection rate of prostate cancer in the Saudi group even with PSA values as high as $10 \mathrm{ng} / \mathrm{mL}$, which suggested an increase in the threshold for taking a TRUS-guided biopsy. This was in line to the results of a study conducted on men aged between 55 to 74 , which reported $19 \%$ as prevalence of prostatic enlargement (13). Through autopsy studies, a histological prevalence of $8 \%, 50 \%$ and $80 \%$ in the 4th, 6th and 9th decades of life, respectively, has been observed (20). In West African men (21), the prevalence of prostate enlargement was $62.3 \%$, which was much higher than our figure. Also, the figures from our study are less than the figures stated for predominantly white populations in the United States 36.3 and $42.0 \%(22,23)$. In the present study, there was no association between senile prostatic enlargement and diabetes mellitus $(43.8 \%$ in diabetics vs. $56.2 \%$ in non-diabetics). Physician-diagnosed diabetes, increased serum insulin and elevated fasting plasma glucose however, have been associated with increased prostate size and an increased risk of prostate enlargement, clinical BPH and BPH surgery in a number of varied cohort studies on tens of thousands of men (24-27). In the present study, there was association between senile prostatic enlargement and obesity $(62.5 \%$ in obese vs. $37.5 \%$ in non obese). Previous studies have reported that increased adiposity is positively associated with prostate volume: The greater the amount of adiposity, the greater the prostate volume. Body mass index has been positively associated with prostate volume in a number of varied study populations (24). Prostate enlargement in obese participants (BMI $\geq 35 \mathrm{~kg} / \mathrm{m}^{2}$ ) had an increased risk of 3.5-fold, compared with non-obese (BMI $<25 \mathrm{~kg} / \mathrm{m}^{2}$ ) participants (28). In summary, our study showed that senile prostatic enlargement is one of the significant important issues in public health in Arar city, Northern Saudi Arabia. The prevalence of this condition reaches 19.3\%, thereby placing even 
greater burden on the quality of life of the elderly and on the health system. While age plays a role in the development of the condition, obesity as a modifiable variable contributes as well. So, we recommend health education sessions to inform the elderly population on how to control their body weight. The availability of drug therapy makes it appropriate for the primary care providers to participate in the management of men with this disorder.

\section{Acknowledgments:}

The success and final outcome of this work required support and assistance of many people, and we are fortunate to have gotten this throughout the completion of the work. Our thanks go to Omar Tabaan M Alenezi and Bader Khalid M Alruwaili (Intern, Northern Border University), Murtadha Mohammed A Bin Abd and Mishael Maki A AlDawood (Intern, Imam Abdulrahman Bin Faisal University), and Muhammad Abdullah M Almalki (Student, Faculty of Medicine NBU) for their help in different steps of the research.

\section{Conflict of Interest:}

There is no conflict of interest to be declared.

\section{Authors' contributions:}

All authors contributed to this project and article equally. All authors read and approved the final manuscript.

\section{References:}

1) Roehrborn CG. Benign Prostatic Hyperplasia: An Overview. Rev Urol. 2005; 7(Suppl 9): S3-14 PMID: 16985902, PMCID: PMC1477638.

2) McVary KT, Roehrborn CG, Avins AL, Barry MJ, Bruskewitz RC, Donnell RF, et al. Update on AUA guideline on the management of benign prostatic hyperplasia. J Urol. 2011; 185: 1793-803. doi: 10.1016/j.juro.2011.01.074. PMID: 21420124.

3) Barry MJ, Fowler FJ Jr, O'Leary MP, Bruskewitz RC, Holtgrewe HL, Mebust WK, et al. The American UrologicalAssociation symptom index for benign prostatic hyperplasia. The Measurement Committee of the American Urological Association. J Urol. 1992; 148(5): 1549-57. doi: 10.1016/S0022-5347(17)369665. PMID: 1279218.

4) Lower urinary tract symptoms in men: management. NICE. 2010.

5) White JM, O'Brien DP. Incontinence and Stream Abnormalities. 3rd edition. Boston: Butterworths; 1990. PMID: 21250138.

6) Urge incontinence. Medline Plus. US National Library of Medicine. 2015.

7) Patel ND1, Parsons JK. Epidemiology and Etiology of Benign Prostatic Hyperplasia and Bladder Outlet Obstruction. Indian J Urol. 2014; 30(2): 170-6. doi: 10.4103/0970-1591.126900. PMID: 24744516, PMCID: PMC3989819.

8) Kapoor A. Benign prostatic hyperplasia (BPH) management in the primary care setting. Can J Urol. 2012; 19 Suppl 1: 10-7. PMID: 23089343.

9) Guess HA, Arrighi HM, Metter EJ, Fozard JL. Cumulative prevalence of prostatism matches the autopsy prevalence of benign prostatic hyperplasia. Prostate. 1990; 17(3): 241. doi: 10.1002/pros.2990170308. PMID: 1700403.

10) Kok ET, Schouten BW, Bohnen AM, Groeneveld FP, Thomas S, Bosch JL. Risk factors for lower urinary tract symptoms suggestive of benign prostatic hyperplasia in a community based population of healthy aging men: The Krimpen study. J Urol. 2009; 181: 710-6. doi: 10.1016/j.juro.2008.10.025. PMID: 19091352.

11) Jacobsen SJ, Jacobson DJ, Girman CJ, Roberts RO, Rhodes T, Guess HA, et al. Natural history of prostatism: Risk factors for acute urinary retention. J Urol. 1997; 158: 481-7. doi: 10.1016/S00225347(01)64508-7. PMID: 9224329.

12) Bosch JL, Hop WC, Kirkels WJ, Schröder FH. Natural history of benign prostatic hyperplasia: Appropriate case definition and estimation of its prevalence in the community. Urology. 1995; 46: 34-40. doi: 10.1016/S0090-4295(99)80248-9. PMID: 7544515.

13) Fong YK, Milani S, Djavan B. Natural history and clinical predictors of clinical progression in benign prostatic hyperplasia. Curr Opin Urol. 2005; 15: 35-8. doi: 10.1097/00042307-200501000-00009. PMID: 15586028. 
14) Guess HA, Arrighi HM, Metter EJ, Fozard JL. Cumulative prevalence of prostatism matches the autopsy prevalence of benign prostatic hyperplasia. Prostate. 1990; 17: 241-6. doi: 10.1002/pros.2990170308. PMID: 1700403.

15) Tantiwong A, Nuanyong C, Vanprapar N, Swasdipala P, Chittapraphai S. Benign prostatic hyperplasia in elderly Thai men in an urban community: The prevalence, natural history and health related behavior. $\mathrm{J}$ Med Assoc Thai. 2002; 85: 356-60. PMID: 12117026.

16) Wei JT, Calhoun E, Jacobsen SJ. Urologic diseases in America project: Benign prostatic hyperplasia. J Urol. 2005; 173: 1256-61. doi: 10.1097/01.ju.0000155709.37840.fe. PMID: 15758764.

17) Egan KB. The Epidemiology of Benign Prostatic Hyperplasia Associated with Lower Urinary Tract Symptoms: Prevalence and Incident Rates. Urol Clin North Am. 2016: 43(3): 289-97. doi: 10.1016/j.ucl.2016.04.001. PMID: 27476122.

18) Alghamidi IG, Hussain II, Alghamdi MS, El-Sheemy MA. The incidence rate of prostate cancer in Saudi Arabia: an observational descriptive epidemiological analysis of data from the Saudi Cancer Registry 2001-2008. Hematol Oncol Stem Cell Ther. 2014; 7(1): 18-26. doi: 10.1016/j.hemonc.2013.10.001. PMID: 24239850.

19) Al-Abdin OZ, Rabah DM, Aprikian A. Differences in prostate cancer detection between Canadian and Saudi populations. Braz J Med Biol Res. 2013; 46: 539-45. doi: 10.1590/1414-431X20132757. PMID: 23802226, PMCID: PMC3854441.

20) Barry MJ, Fowler FJ Jr, Bin L, Pitts JC 3rd, Harris CJ, Mulley AG Jr. The natural history of patients with benign prostatic hyperplasia as diagnosed by North American urologists. J Urol. 1997; 157: 10-4. doi: 10.1016/S0022-5347(01)65267-4. PMID: 8976204.

21) Chokkalingam AP, Yeboah ED, Demarzo A, Netto G, Yu K, Biritwum RB, et al. Prevalence of BPH and lower urinary tract symptoms in West Africans. Prostate Cancer Prostatic Dis. 2012; 15(2): 170-6. doi: 10.1038/pcan.2011.43. PMID: 21912428.

22) Naslund MJ, Gilsenan AW, Midkiff KD, Bown A, Wolford ET, Wang J. Prevalence of lower urinary tract symptoms and prostate enlargement in the primary care setting. Int J Clin Pract. 2007; 61: 1437-45. doi: 10.1111/j.1742-1241.2007.01508.x. PMID: 17686091.

23) Guess HA, Arrighi HM, Metter EJ, Fozard JL. Cumulative prevalence of prostatism matches the autopsy prevalence of benign prostatic hyperplasia. Prostate. 1990; 17: 241-6. doi: 10.1002/pros.2990170308. PMID: 1700403.

24) Parsons JK, Sarma AV, McVary K, Wei JT. Obesity and benign prostatic hyperplasia: Clinical connections, emerging etiological paradigms and future directions. J Urol. 2013; 189: S102-6. doi: 10.1016/j.juro.2012.11.029. PMID: 23234610.

25) Sarma AV, Parsons JK, McVary K, Wei JT. Diabetes and benign prostatic hyperplasia/lower urinary tract symptoms--what do we know? J Urol. 2009; 182: S32-7. doi: 10.1016/j.juro.2009.07.088. PMID: 19846144.

26) Parsons JK, Bergstrom J, Barrett-Connor E. Lipids, lipoproteins and the risk of benign prostatic hyperplasia in community-dwelling men. BJU Int. 2008; 101: 313-8. doi: 10.1111/j.1464-410X.2007.07332.x. PMID: 18005202, PMCID: PMC2647139.

27) Gupta A, Gupta S, Pavuk M, Roehrborn CG. Anthropometric and metabolic factors and risk of benign prostatic hyperplasia: A prospective cohort study of Air Force veterans. Urology. 2006; 68: 1198-205. doi: 10.1016/j.urology.2006.09.034. PMID: 17169643.

28) Parsons JK. Modifiable risk factors for benign prostatic hyperplasia and lower urinary tract symptoms: New approaches to old problems. J Urol. 2007; 178: 395-401. doi: 10.1016/j.juro.2007.03.103. PMID: 17561143. 